\title{
SHARP ESTIMATES REGARDING THE REMAINDER OF THE ALTERNATING HARMONIC SERIES
}

\author{
ALINA SînTĂMĂRIAN
}

Abstract. In the present paper we obtain enhanced estimates regarding the remainder of the alternating harmonic series. More precisely, we show that

$$
\frac{1}{4 n^{2}+a}<\left|\sum_{k=1}^{n}(-1)^{k-1} \frac{1}{k}-(-1)^{n-1} \frac{1}{2 n}-\ln 2\right| \leqslant \frac{1}{4 n^{2}+b},
$$

for all $n \in \mathbb{N}$, with $a=2$ and $b=\frac{2(3-4 \ln 2)}{2 \ln 2-1}=1.177398899 \ldots$ In addition, the constants $a$ and $b$ are the best possible with the above-mentioned property. Mathematics subject classification (2010): 11 Y 60, 40A05, 41A44, 33B15.

Keywords and phrases: Alternating harmonic series, harmonic number, digamma function, EulerMascheroni constant, best constant.

\section{REFERENCES}

[1] H. Alzer, Inequalities for the gamma and polygamma functions, Abh. Math. Sem. Univ. Hamburg 68 (1998), 363-372

[2] C.-P. CHEN, Inequalities for the Euler-Mascheroni constant, Appl. Math. Lett. 23, 2 (2010), 161-164.

[3] C.-P. CHEN AND F. QI, The best lower and upper bounds of harmonic sequence, RGMIA 6, 2 (2003), 303-308.

[4] C.-P. Chen And C. Mortici, New sequence converging towards the Euler-Mascheroni constant, Comput. Math. Appl. 64, 4 (2012), 391-398.

[5] C.-P. Chen And H. M. SRivastaVa, New representations for the Lugo and Euler-Mascheroni constants, Appl. Math. Lett. 24, 7 (2011), 1239-1244.

[6] O. Furdui, Limits, Series, and Fractional Part Integrals. Problems in Mathematical Analysis, Springer, New York (2013).

[7] I. S. Gradshteyn And I. M. Ryzhik, Table of Integrals, Series, and Products (7th ed.), Elsevier/Academic Press, Amsterdam (2007).

[8] B.-N. GUo AND F. QI, Sharp bounds for harmonic numbers, Appl. Math. Comput. 218, 3 (2011), 991-995.

[9] D. K. KaZARINOFF, A simple derivation of the Leibniz-Gregory series for $\pi / 4$, Amer. Math. Monthly 62, 10 (1955), 726-727.

[10] F. W. J. Olver (ed.), D. W. Lozier (ed.), R. F. Bois vert (ed.) and C. W. Clark (ed.), NiST Handbook of Mathematical Functions, Cambridge University Press, Cambridge, 2010.

[11] W. Rautenberg, Zur Approximation von e durch $\left(1+\frac{1}{n}\right)^{n}$ (On the approximation of $e$ by $\left(1+\frac{1}{n}\right)^{n}$ ), Math. Semesterber. 33 (1986), 227-236.

[12] A. SînTĂMĂRIAN, A new proof for estimating the remainder of the alternating harmonic series, Creat. Math. Inform. 21, 2 (2012), 221-225.

[13] L. Tóth, Problem E3432, Amer. Math. Monthly 98, 3 (1991), 264.

[14] L. Tóth, Problem E3432 (Solution), Amer. Math. Monthly 99, 7 (1992), 684-685.

[15] L. Tóth, On a class of Leibniz series, Rev. Anal. Numér. Théor. Approx. 21, 2 (1992), 195-199.

[16] L. Tóth AND J. BuKor, On the alternating series $1-\frac{1}{2}+\frac{1}{3}-\frac{1}{4}+\cdots$, J. Math. Anal. Appl. 282, 1 (2003), 21-25. 